\title{
Mindfulness and Cognitive Depletion Shape the Relationship between Moral Conviction and Intolerance of Dissimilar Others
}

\author{
Jennifer N. Baumgartner \\ University of California San Diego, USA
}

\author{
G. Scott Morgan \\ Drew University, USA
}

\begin{abstract}
When people vest a position with moral conviction, that is, a sense that the position is grounded in fundamental right or wrong, good or bad, they tend to be particularly intolerant of those who disagree. Psychological states that mitigate or augment the effect of moral conviction on tolerance are lesser known. The present research investigated the immediate consequences of mindfulness and mindlessness (cognitive depletion) on the relationship between moral conviction and preferred social distance. Consistent with hypotheses, moral conviction did not predict preferred social distance in a mindfulness condition (mindfulness meditation), predicted greater preferred social distance in a mindlessness condition (cognitive depletion), and predicted marginally greater preferred social distance in a control condition (no manipulation). Findings suggest that adopting a mindful orientation toward people with different moral views may foster acceptance, while adopting a mindless orientation may foster greater intolerance.
\end{abstract}

Key words: moral conviction, mindfulness, social distance, intolerance, cognitive depletion

Popular discourse suggests that society is becoming increasingly polarized along ideological and moral lines (Doherty, Kiley, \& Jameson, 2016). Psychological literature has documented people's intolerance of those with whom they disagree (see Brandt, Reyna, Chambers, Crawford, \& Wetherell, 2014). People tend to be especially intolerant of those who disagree with them on issues that they vest with moral conviction - positions experienced as grounded in fundamental right and wrong, good and bad (Skitka, Bauman, \& Sargis, 2005; Wright, Cullum, $\&$ Schwab, 2008). The present research investigated states that may modulate this effect, and in particular, whether mindfulness ameliorates

Correspondence concerning this article should be addressed to Jennifer N. Baumgartner, University of California San Diego, USA. E-mail: jebaumgartner@ucsd.edu

Received August 7, 2018 and mindlessness amplifies the tendency to be intolerant of moral disagreement.

\section{Moral Conviction}

A robust body of work shows that attitudes vested with moral conviction - known as moral mandates - differ from non-moral attitudes in a number of ways (for a review, see Skitka \& Morgan, 2014). Moral mandates are associated with stronger emotions than non-moral attitudes (Skitka \& Wisneski, 2010). Moral mandates are also authority independent. When people vest an attitude with moral conviction, they are more likely to believe that related duties and rights follow from moral principles rather than rules, procedures, or authority dictates (e.g., Skitka, Bauman, \& Lytle, 2009). Furthermore, moral mandates inoculate people against peer influence. The stronger a person's moral conviction, the less likely that person will conform to others with a contrary position (Skitka, Aramovich, 
Lytle, \& Sargis, 2010). Additionally, moral mandates are a barrier to conflict resolution. Moral disagreement fosters less cooperation, less goodwill, and greater difficulty in reaching a consensus (Skitka et al., 2005). Finally, greater moral conviction predicts attitude-consistent behaviors such as voting or political protest (Morgan, Skitka, \& Wisneski, 2010; van Zomeren, Postmes, \& Spears, 2012).

Of importance to the current research, moral mandates are characterized by greater social intolerance and discrimination toward attitudinally dissimilar others (Skitka et al., 2005; Wright et al., 2008). Altogether, the differences between moral mandates and non-moral attitudes beg the question: what factors impact the effect of moral conviction on intolerance? Specifically, what factors exacerbate the tendency to be intolerant of those with whom one disagrees on deeply held moral views? Moreover, what factors weaken or undo intolerance of moral disagreement? The present research seeks to provide insight into these timely questions.

\section{Mindfulness}

One state that may weaken or undo the effect of moral conviction on intolerance is mindfulness. A relatively early and social psychologically situated conceptualization of mindfulness describes it as a state of "active and fluid information processing, sensitivity to context and multiple perspectives, and an ability to draw novel distinctions" (Langer, 1989, p. 138). However, other conceptualizations of mindfulness, indeed the focus of the current investigation, define mindfulness as a broad construct involving states and processes that enhance attention to and awareness of moment-to-moment sensory experience without judgment or reactivity (Brown \& Ryan, 2003; Kabat-Zinn, 1990; Lutz, Jha, Dunne, \& Saron, 2015). Importantly, a theme that seems to crosscut definitions is a certain phenomenology whereby experience is broadened, and stimuli are attended to and processed in an enhanced manner.

Mindfulness has been shown to shape interpersonal relationships. One study found that modified mindfulness-based stress reduction (MBSR) increased reports of empathy in premedical and medical students compared to the controls (Shapiro, Schwartz, \& Bonner, 1998). Beyond subjective ratings, mindfulness and compassion meditation increased actual helping behavior toward suffering individuals (Condon, Desbordes, Miller, \& DeSteno, 2013). Brief mindfulness meditation interventions also have interpersonal consequences. Compared to active and relaxation control groups, five (Tan, Yo, \& Macrae, 2014) and eight minute (Berry et al., 2018) inductions of mindfulness increased empathetic responses toward ostensibly ostracized strangers. However, it is unknown whether the prosocial benefits of mindfulness extend to those with whom a person morally disagrees.

There are reasons to suggest that mindfulness may facilitate tolerance of morally dissimilar others. One could reasonably construe responses to those who oppose their moral mandates as a form of moral judgment - one that is intuitive and automatic (Haidt, 2001; but see Wisneski \& Skitka, 2017). Conversely, research suggests that automatic cognitive processes can be brought under control through mindfulness. Experienced mindfulness meditators compared to novices exhibited greater inhibitory control and cognitive flexibility during executive control tasks (Moore \& Malinowski, 2009). Similarly, participants who received MBSR training demonstrated superior attention orienting, compared to untrained participants (Jha, Krompinger, \& Baime, 2007). An emphasis on the core processes of mindfulness, that is, on nonjudgement and nonreactivity, warrant consideration here (Bishop et al., 2004; Kabat-Zinn, 2003). We suspect that these are the "active 
ingredients" that should cultivate a mental stance where no single viewpoint, conviction, or emotion is privileged over another. Collectively, the enhanced control of automatic processes, coupled with greater acceptance should foster openness and receptivity of others despite potential opposing convictions.

\section{Mindlessness}

Mindfulness and so-called "mindlessness" can be considered opposing constructs with respects to attentional engagement and information processing (Brown \& Ryan, 2003; Langer, 1989), and thus may affect tolerance in different ways. Whereas mindfulness represents a state of open and fluid information processing, mindlessness represents depletion of attentional control and information processing (Langer, 1989). During mindlessness, thought and behavior occur in an automatic fashion without much participation of the individual to override impulsive or inappropriate actions. As a result, people are susceptible to over reliance on established categories, simple decision-making errors (Pohl, Erdfelder, Hilbig, Liebke, \& Stahlberg, 2013), and, critical to the present investigation, prejudice toward outgroup members (Muraven, 2008).

Research also suggests that social processes are impacted by mindlessness. A cognitive depletion manipulation reduced rating of empathetic concern and diminished neural responses in brain regions associated with empathy (Morelli \& Lieberman, 2013). Interestingly, other research suggests mindlessness influences moral judgments. Participants instructed to perform a number identification task while reading moral dilemmas had increased decision making time for utilitarian moral judgments compared to non-utilitarian judgments (Greene, Morelli, Lowenberg, Nystrom, \& Cohen, 2008). This suggests that some aspects of moral judgments depend on controlled cog- nitive processes. It is possible that depletion of cognitive resources through mindlessness promotes greater intolerance, while control of cognitive resources through mindfulness promotes tolerance.

\section{The Present Research}

Integrating across the diverse literatures, we examined the influence of mindfulness and mindlessness on the interpersonal consequences of moral conviction. We hypothesized that moral conviction would have a weak or non-significant effect on preferred social distance for participants in the mindfulness condition (mindfulness meditation), and would predict increased social distance for participants in the mindlessness (cognitive depletion) and control (no manipulation) conditions.

\section{Method}

\section{Participants}

Ninety-seven undergraduate students (age $M=19.24, S D=1.40$ ) from a large and diverse, public Midwestern university participated in exchange for partial course credit. The majority were male $(n=52)$. Most participants reported being Asian $(n=33)$, followed by Hispanic $(n=$ $25)$, Caucasian $(n=20)$, African American $(n=$ $13)$, and other $(n=6)$.

Demographic information by experimental conditions (mindfulness, mindlessness, and control) is displayed in Table 1. Age was evenly distributed across groups, $F(2,97)=.31, p=$ .74 , as was gender, $\chi^{2}(2)=.21, p=.90$, and ethnicity, $\chi^{2}(82)=76.09, p=.66$, indicating successful randomization.

\section{Procedure}

Twenty-four hours before the experimental session, participants reported their position on 
Table 1 Demographic characteristics by mindfulness, mindlessness, and control conditions

\begin{tabular}{lccc}
\hline & Mindfulness & Mindlessness & Control \\
\hline Age in years $(M, S D)$ & $19.26(1.48)$ & $19.35(1.63)$ & $19.07(.98)$ \\
Sex $(\%$ female) & $47 \%$ & $47 \%$ & $43 \%$ \\
Ethnicity (\% Caucasian) & $25 \%$ & $20 \%$ & $20 \%$ \\
\hline
\end{tabular}

legalized abortion. Abortion was selected as the issue-at-hand because it is a particularly polarizing topic in the American context, and was a focus of previous research on the link between moral conviction and intolerance (Skitka et al., 2005). Participants completed a measure of attitude strength and moral conviction regarding their position. Five participants at a time reported to the laboratory and were randomly assigned to one of the three conditions: mindfulness, mindlessness, or no-intervention control (see Experimental Conditions). Then, participants reported their preferred social distance from those who disagreed with their position on abortion. Participants were fully debriefed and thanked for their time. All experimental procedures were approved by the local ethics review board.

\section{Experimental Conditions}

Mindfulness. Participants assigned to the mindfulness condition $(n=34)$ received written instructions and guided focused attention mindfulness meditation from an experienced meditator (adapted from Kabat-Zinn, 1990). While seated in a chair, participants were instructed to voluntarily and without judgment sustain their attention on breath sensation for 15 minutes to evoke a state of present moment awareness. They were told that if their mind began to wander, they should take notice of the wandering, and gently, without judgment, bring their attention back to the breath. Thus, this mindfulness manipulation was oriented toward focused attention on the dynamics of inner experience (Lutz et al., 2015).

The majority of participants ( $n=24,71 \%$ ) assigned to the mindfulness condition were meditation novices, that is, reported no prior experience with meditation practices. Onlytwo participants $(5 \%)$ reported having "moderate" meditation experience. The majority ofparticipants $(n=$ $20,60 \%$ )reported dedicating "much" effort to the mindfulness exercise, thought the exercise was "very interesting" $(n=22,63 \%)$, and felt "very relaxed" during the exercise $(n=15,43 \%)$.

Mindlessness (cognitive depletion). Participants assigned to the mindlessness condition $(n=35)$ completed a modified version of the Attention Network Test (Fan, McCandliss, Sommer, Raz, \& Posner, 2002), which is a computerized measure of attention. This modified task was used to evoke cognitive depletion, and has been used for this purpose in past research (Apfelbaum \& Sommers, 2009). Participants were presented with strings of five congruent or incongruent arrows and were asked to determine the direction the center arrow was pointing relative to the other four arrows. Correct responses to incongruent arrows require executive control to override the automatic tendency to follow the direction of the arrows, thus evoking depletion over consecutive trials. As with the meditation condition, participants performed this task for 15 minutes.

No-intervention control. Participants assigned to the control condition $(n=28)$ completed self-report assessments, but did not experience either state induction. 


\section{Pre-Measures}

Position. Participants reported their position on legalized abortion by responding to the question, "What is your stance on abortion?" using a 3-point scale with the point labels of support, oppose, and other/neither support nor oppose. Position was coded as 1 = support, $-1=$ oppose, and $0=$ other/neither support nor oppose.

Attitude importance. Participants reported the extent to which their position on abortion was "important to you", "something you care about", and "important to you compared to other issues" using a 5-point scale ranging from not at all to very much (Skitka et al., 2005). Responses were averaged into a single score $(\alpha=$ .90).

Moral conviction. Participants reported the extent to which their position on abortion was "connected to your beliefs about fundamental right or wrong", "a reflection of your core moral beliefs or convictions, 'a moral stance', and based on a moral principle" using a 5-point scale ranging from not at all to very much (Skitka et al., 2005). Responses were averaged into a single score $(\alpha=.96)$.

Although it would be possible to measure abortion attitudes using a bipolar scale that ranged from very much opposed to very much support (with neither oppose nor support as the midpoint), we elected to separately measure the valence of each participant's position and the strength of their position (attitude importance is a common measure of attitude strength; Petty \& Krosnick, 1995). This approach is consistent with that used in other moral conviction research (Skitka et al., 2005; Skitka et al., 2012), and allows a) for position and strength to be entered as separate variables in the analyses, and $b$ ) for more direct comparisons of the effects of attitude strength and moral conviction (both of which are measured on 5-point scales). In short, this approach allows us to more effec- tively test whether moral conviction's effects on intolerance are due to morality and not attitude strength.

\section{Post-Measures}

Preferred social distance. Participants reported the extent to which they would be happy to have someone who did not share their views on abortion as "President", "Governor", "my neighbor", "a coworker", "a roommate", "to marry into my family", "someone I would date", "my personal physician", "a close friend", "the owner of a store or restaurant I frequent", "the teacher of my children", and "my spiritual advisor" (Skitka et al., 2005) using a 5-point scale ranging from not at all to very much. Responses were reversed scored and then averaged into a single score $(\alpha=.89)$.

\section{Results}

Study variables were normally distributed as indicated by skewness and kurtosis values. $\mathrm{Bi}$ variate correlations are presented in Table 2. Briefly, reporting strong moral conviction about abortion was positively correlated with attitude importance $(r=.58, p<.01)$. Moral conviction was also positively correlated with preferred social distance $(r=.28, p<.01)$.

Before conducting primary analyses, we ensured the assumptions for multiple regression were met. Tolerance and VIF values were within an acceptable range, indicting there was no multicollinearity among predictors. The DurbinWatson statistic indicated that residuals were independent, and lastly, an examination of the residuals indicated there was no problematic variation.

Multiple linear regression tested hypotheses that psychological state would modulate the relationship between moral conviction and preferred social distance. Gender, age, position on abortion, condition, importance, moral convic- 
tion, followed by the interaction of importance and moral conviction with condition were entered as independent variables. Moral conviction and importance were mean centered before computing the interaction terms, and because both variables were highly correlated $(r=.58)$. Preferred social distance was entered as the dependent variable. Conditions were dummy coded as $1=$ mindfulness, $-1=$ mindlessness, and $0=$ control.
The overall model was significant, $F(8,96)=$ $2.20, p<.05, \eta^{2}=.167$, accounting for $16.7 \%$ of the variance in preferred social distance. As seen in Table 3, moral conviction predicted marginally greater preferred social distance $(\beta=$ $-16, p=.08,95 \%$ CI $[-.02, .34])$. This effect was qualified by a moral conviction by condition interaction $(\beta=-.23, p<.05,95 \% \mathrm{CI}[-.44 .-.01])$. As seen in Table 4, follow-up regression analyses revealed that moral conviction was unre-

Table 2 Descriptive statistics and bivariate correlations among study variables

\begin{tabular}{llrccccc}
\hline & $M$ & $S D$ & 1 & 2 & 3 & 4 & 5 \\
\hline 1. Age & 19.24 & 1.40 & - & & & & \\
2. Position & .00 & .80 & -.04 & - & & & \\
3. Importance & 2.98 & .96 & .15 & $-.28^{* *}$ & - & & \\
4. Moral conviction & 3.44 & 1.11 & .11 & $-.47^{* *}$ & $.58^{* *}$ & - & \\
5. Condition & .01 & .85 & -.03 & -.06 & -.00 & .05 & - \\
6. Preferred social distance & 3.41 & .74 & -.08 & $-.28^{* *}$ & .15 & $.28^{* *}$ & -.01 \\
\hline
\end{tabular}

Note. Position on abortion was coded as $1=$ support, $-1=$ oppose, and $0=$ other/neither support nor oppose.

Conditions were coded as $1=$ mindfulness, $-1=$ mindlessness, and $0=$ control.

${ }^{*} p<.05, \stackrel{* *}{p}<.01$.

Table 3 Unstandardized regression coefficients of predictors of preferred social distance

\begin{tabular}{lcccc}
\hline & $B$ & $S E$ & $t$ & $p$ \\
\hline Gender & .01 & .16 & .07 & .95 \\
Age & -.06 & .05 & -1.13 & .26 \\
Position & -.17 & .10 & -1.63 & .12 \\
Condition & -.03 & .09 & -.37 & .71 \\
Importance (imp) & -.02 & .10 & -.21 & .84 \\
Moral conviction (MC) & .16 & .09 & 1.80 & $.08^{\dagger}$ \\
Condition x Imp & .12 & .12 & .98 & .33 \\
Condition x MC & -.23 & .11 & -2.11 & $.04^{*}$ \\
\hline
\end{tabular}

Note. Gender was coded as $1=$ male and $2=$ female.

Position on abortion was coded as $1=$ support, $-1=$ oppose, and $0=$ other/neither support nor oppose.

Conditions were coded as $1=$ mindfulness, $-1=$ mindlessness, and $0=$ control. ${ }^{*} p<.05,{ }^{\dagger} p<.10$. 


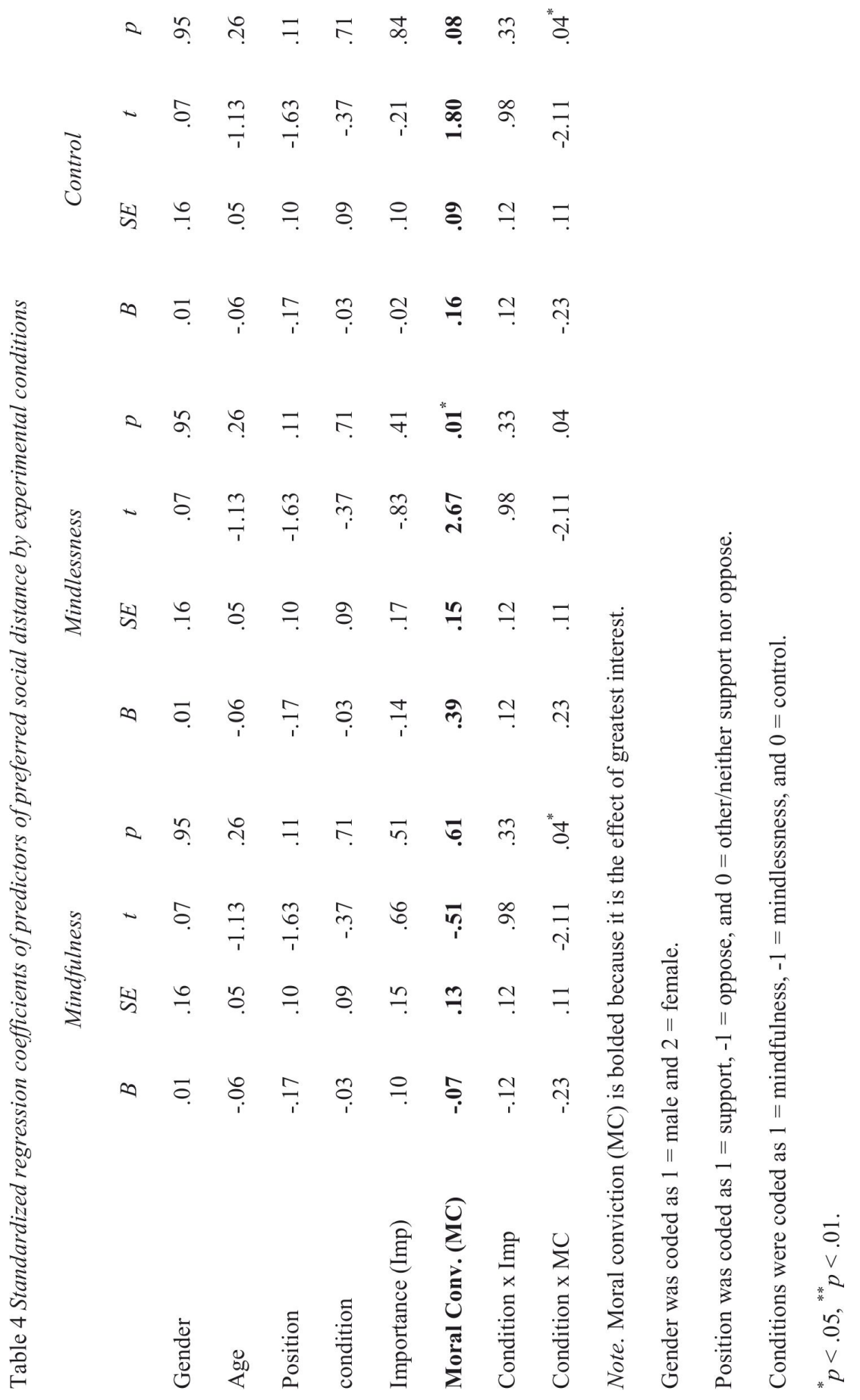


lated to preferred social distance in the mindfulness condition $(\beta=-.07, p=.61,95 \%$ CI [-.34, $.20]$ ), predicted greater preferred social distance in the mindlessness condition $(\beta=.39, p<.01$, $95 \%$ CI $[.10, .68])$, and predicted marginally greater preferred social distance in the control condition $(\beta=.08, p=.08,95 \%$ CI $[-.02, .34])$, which were consistent with the hypotheses.

\section{Discussion}

Under typical conditions, people are intolerant of others who disagree with them on issues they vest with moral conviction. The present research documents factors that modulate this effect. A brief induction of mindfulness facilitated a more neutral, equanimous stance toward morally dissimilar others, whereas a brief induction of mindlessness facilitated greater intolerance.

There may be a number of reasons for the mitigating effect of mindfulness on the relationship between moral conviction and preferred social distance. One of the more robust outcomes of mindfulness is in the domain of emotion regulation (Chambers, Gullone, \& Allen, 2009; Lutz, Slagter, Dunne, \& Davidson, 2008; Sedlmeier et al., 2012). The brief induction of mindfulness may have influenced reactions or appraisals of potentially intense affective signals normally experienced when discerning moral judgment. Indeed, the domain theory of attitudes suggests that moral reactions facilitate more intense emotions than emotions experienced as a consequence of non-moral attitudes (Skitka, 2014). Consistent with this theory, participants who rated a vignette of incest as immoral experienced more intense negative affective than those who thought the vignette was less immoral (Royzman, Leeman, \& Sabini, 2008). Conversely, and by its definition, mindfulness promotes non-reactivity to discursive sensory experiences (Kabat-Zinn, 1990). Supporting this, mindfulness training reduces the frequency and intensity of negative affect (Brown \& Ryan, 2003) and increases positive affect (Teasdale et al., 2000). Taken together, the induction of mindfulness may have neutralized or downregulated affective signals typically experienced as a result of moral reactions, allowing one to engage in more careful and accepting moral judgments.

A surprising finding from the current research is the potency of mindlessness on preferred social distance. Our findings indicate that depletion of cognitive resources make people more extreme in their intolerance of morally dissimilar others. This extends past research showing that certain cognitive states can make people more intolerant of others. Participants who experienced disgust due to a dirty laboratory made harsher moral judgments compared to judgments made in a clean laboratory (Schnall, Haidt, Clore, \& Jordan, 2008). Furthermore, our findings provide the interpersonal consequences to the effect that sustained attentional demands consume executive resources, leading to a decline in subsequent performance (see Beilock, Carr, MacMahon, \& Starkes, 2002; Zanesco, King, MacLean, \& Saron, 2013). Thus, it appears that the relationship between moral conviction and intolerance depends, at least partially, on the ability to regulate cognitive and affective systems in a momentary fashion, with depletion making people more extreme in their desire for disconnection.

In addition to the theoretical implications of this work, our findings also have some practical implications. Political polarization in the United States is now greater than at any point in the last several decades (Pew Research, 2014) and has been described as "alarmingly high" (Westfall, Van Boven, Chambers, \& Judd, 2015). Furthermore, across the political spectrum, people are intolerant of those with whom they disagree (Brandt et al., 2014; Crawford, 2012 ; 2014). Thus, any research that suggests strategies to reduce intolerance provides po- 
tentially useful information in our contentious sociopolitical climate. The strategy at the center of this research - mindfulness training has already been shown to have a number of pro-social benefits (for a review, see Condon, 2018) and the current research suggests an additional benefit: decreased intolerance toward those across the political aisle. Although there are clear obstacles when it comes to reaping the political benefits of mindfulness training, one could imagine that some practical pieces of advice, notably, schools, organizations, and institutions (perhaps even government institutions), could implement short-term mindfulness training when preparing people to discuss contentious issues. On a grander level, an open question is whether wide-spread mindfulness training (perhaps implemented in the education system) could help build a more tolerant society.

The present research has some limitations and provides avenues for future inquiry. Mindfulness research has fallen under scrutiny by the lack of active control groups (see Davidson \& Kaszniak, 2015). Because the present research used a no intervention control group, it is possible that findings may not be due to mindfulness specifically, but to other nonspecific factors such as general relaxation. Future research should investigate the role of mindfulness and mindlessness on intolerance using time and attention-matched control groups. Future research would also benefit from shifting from a state approach to a trait approach in order to examine whether long-term or intensive meditation training impacts tolerance. Lastly, mindfulness was not measured in the current study, and can only be inferred from the brief mindfulness induction. Therefore, we cannot ascertain conclusively that mindfulness was the precise mechanism of change.

Taken together, the present research aimed to provide the first inquiry into the effect of moral conviction on social distance after adopt- ing a mindful or mindless orientation. In daily life, moral conviction predicts greater social distance from attitudinally dissimilar others. However, this effect can be reduced while in a mindful state or greatly augmented while in a mindless state. This study provides insight in ways to dissolve intolerance toward others who perceive their world in morally different terms findings that are critical for navigating a complex and polarized social world.

\section{References}

Apfelbaum, E. P., \& Sommers, S. R. (2009). Liberating effects of losing executive control: When regulatory strategies turn maladaptive. Psychological Science, 20, 139-143. http://dx.doi.org/10.1111/j. 1467-9280.2009.02266.x

Beilock, S. L., Carr, T. H., MacMahon, C., \& Starkes, J. L. (2002). When paying attention becomes counterproductive: Impact of divided versus skill-focused attention on novice and experienced performance of sensorimotor skills. Journal of Experimental Psychology: Applied, 1, 6-16. http://dx.doi.org/10. 1037/1076-898X.8.1.6

Berry, D. R., Cairo, A. H., Goodman, R. J., Quaglia, J. T., Green, J. D., \& Brown, K. W. (2018). Mindfulness increases prosocial responses toward ostracized strangers through empathic concern. Journal of Experimental Psychology: General, 147, 93-112. http://dx.doi.org/10.1037/xge0000392

Bishop, S. R., Lau, M., Shapiro, S. L., Carlson, L., Anderson, N. D., ... \& Devins, G. (2004). Mindfulness: A proposed operational definition. Clinical Psychology; Science and Practice, 11, 230-241. https://doi.org/10.1093/clipsy.bph077

Brandt, M. J., Reyna, C., Chambers, J. R., Crawford, J. T., \& Wetherell, G. (2014). The ideologicalconflict hypothesis: Intolerance among both liberals and conservatives. Current Directions in Psychological Science, 23, 27-34. https://doi.org/10.1177/ 0963721413510932

Brown, K. W., \& Ryan R. M. (2003). The benefits of being present: Mindfulness and its role in psychological well-being. Journal of Personality and Social Psychology, 84, 822-848. http://dx.doi.org/ 10.1037/0022-3514.84.4.822

Chambers, R., Gullone, E., \& Allen, N. B. (2009). Mindful emotion regulation: An integrative review. Clinical Psychology Review, 29, 560-572. https://doi.org/ 10.1016/j.cpr.2009.06.005 
Condon, P. (2018, October 25). Meditation in context: Factors that facilitate prosocial behavior. https://doi.org/10.1016/j.copsyc.2018.09.011.

Condon, P., Desbordes, G., Miller, W. B., \& DeSteno, D. (2013). Meditation increases compassionate responses to suffering. Psychological Science, 24, 13. doi: 10.1177/0956797613485603.

Crawford, J. T., \& Pilanski, J. M. (2012). Political intolerance, right and left. Political Psychology, 35(6), 841-851. doi: 10.1177/0956797613485603

Crawford, J. T. (2014). Ideological symmetries and asymmetries in political intolerance and prejudice toward political activist groups. Journal of Experimental Social Psychology, 55, 284-298. http:// dx.doi.org/10.1016/j.jesp.2014.08.002

Davidson, R. J., \& Kaszniak, A. W. (2015). Conceptual and methodological issues in research on mindfulness and meditation. American Psychologist, 70, 581-592. doi: 10.1037/a0039512

Dimock, N., Doherty, C., Kiley, J., \& Oates, R. (2014). Political polarization in the American public: How increasing ideological uniformity and partisan antipathy affect politics, compromise and everyday life. Washington, DC: Pew Research Center. https:// doi.org/10.1177/1745691615569849

Fan, J., McCandliss, B. D., Sommer, T., Raz, A., \& Posner, M. I. (2002). Testing the efficiency and independence of attentional networks. Journal of Cognitive Neuroscience, 14, 340-347. doi: 10.1162/ 089892902317361886

Greene, J. D., Morelli, S. A., Lowenberg, K., Nystrom, L. E., \& Cohen, J. D. (2008). Cognitive load selectively interferes with utilitarian moral judgement. Cognition, 107, 1144-1154. doi: 10.1016/ j.cognition.2007.11.004

Haidt, J. (2001). The emotional dog and its rational tail: A social intuitionist approach to moral judgement. Psychological Review, 108, 814-834. doi: 10.1037//0033-295X.108.4.814

Jha, A. P., Krompinger, J., \& Baime, M. J. (2007). Mindfulness training modifies subsystems of attention. Cognitive, Affective, and Behavioral Neuroscience, 7, 109-119. doi:10.3758/CABN.7.2. 109

Kabat-Zinn, J. (1990). Full catastrophe living: The program of the Stress Reduction Clinic at the University of Massachusetts Medical Center. New York, NY: Delacorte Press, Dell Publishing.

Kabat-Zinn, J. (2003). Mindfulness-based interventions in context: Past, present, future. Clinical Psychology: Science and Practice, 10, 144-156. https:// doi.org/10.1093/clipsy.bpg016

Langer, E. J. (1989). Minding matters: The consequences of mindlessness-mindfulness. In L. Berkowistz (Ed.), Advances in experimental psychol- ogy, Vol. 22 (pp. 137-173). San Diego, CA: Academic Press. http://dx.doi.org/10.1016/S00652601(08)60307-X

Lutz, A., Jha, A. P., Dunne, J. D., \& Saron, C. D. (2015). Investigating the phenomenological matrix of mindfulness-related practices from a neurocognitive perspective. American Psychologist, 70, 632-658. doi: 10.1037/a0039585

Lutz, A., Slagter, H. A., Dunne, J. D., \& Davidson, R. J. (2008). Attention regulation and monitoring in meditation. Trends in Cognitive Sciences, 12, 163169. doi: 10.1016/j.tics.2008.01.005

Moore, A., \& Malinowski, P. (2009). Meditation, mindfulness, and cognitive flexibility. Consciousness and Cognition, 18, 176-186. doi: 10.1016/j.concog. 2008.12.008

Morelli, S. A., \& Lieberman, M. D. (2013). The role of automaticity and attention in neural processes underlying empathy for happiness, sadness, and anxiety. Frontiers in Human Neuroscience, 7, 1-15. doi: 10.3389/fnhum.2013.00160

Morgan, G. S., Skitka, L. J., \& Wisneski, D. C. (2010). Moral and religious convictions and intentions to vote in the 2008 presidential election. Analysis of Social Issues and Public Policy, 10, 307-320. http://dx.doi.org/10.1111/j.1530-2415.2010. 01204.x

Muraven, M. (2008). Prejudice as self-control failure. Journal of Applied Social Psychology, 38, 314-333. http://dx.doi.org/10.1111/j.1559-1816.2007. 00307.x

Petty, R. E., \& Krosnick, J. A. (1995). Attitude strength: Antecedents and consequences. Mahwah, NJ Erlbaum.

Pew Research Center (2014). Political polarization in the American public. Retrieved from: http:// www.people-press.org/2014/06/12/political-polarization-in-the-american-public/

Pohl, R. F., Erdfelder, E., Hilbig, B. E., Liebke, L., \& Stahlberg, D. (2013). Effort reduction after selfcontrol depletion: The role of cognitive resources in use of simple heuristics. Journal of Cognitive Psychology, 25, 267-276. https://doi.org/10.1080/ 20445911.2012 .758101

Royzman, E. B., Leeman, R. F., \& Sabini, J. (2008). "You make me sick": Moral dyspepsia as a reaction to third-party sibling incest. Motivation and Emotion, 32, 100-108. http://dx.doi.org/10.1007/ s1 1031-008-9089-x

Schnall, S., Haidt, J., Clore, G. L., \& Jordan, A. H. (2008). Disgust as embodied moral judgment. Personality and Social Psychology Bulletin, 8, 10961109. doi: 10.1177/0146167208317771

Sedlmeier, P., Eberth, J., Schwarz, M., Zimmermann, D., Haarig, F., Jaeger, S., \& Kunze, S. (2012). The 
psychological effects of meditation: A meta-analysis. Psychological Bulletin, 138, 1139-1171. doi: 10.1037/a0028168

Shapiro, S. L., Schwartz, G. E., \& Bonner, G. (1998). Effects of mindfulness-based stress reduction on medical and premedical students. Journal of Behavioral Medicine, 21, 581-599. http://dx.doi.org/ 10.1023/A:1018700829825

Skitka, L. J. (2014). The psychological foundations of moral conviction. In J. Wright \& H. Sarkissian (Eds.), Advances in Moral Psychology, Bloomsbury Academic Press (pp. 148-166), New York, NY.

Skitka, L. J., Aramovich, N., Lytle, B. L., \& Sargis, E. (2009). Knitting together an elephant: An integrative approach to understanding the psychology of justice reasoning. In D. R. Bobocel, A. C. Kay, M. P. Zanna, \& J. M. Olson (Eds.), The psychology of justice and legitimacy: The Ontario symposium, Vol. 11 (pp. 1-26). Philadelphia, PA: Psychology Press.

Skitka, L. J., Bauman, C. W., \& Lytle, B. L. (2009) Limits on legitimacy: Moral and religious convictions as constraints on deference to authority. Journal of Personality and Social Psychology, 97(4), 567-578. doi: 10.1037/a0015998

Skitka, L. J., Bauman, C. W., \& Sargis, E. G. (2005). Moral conviction: Another contributor to attitude strength or something more? Journal of Personality and social Psychology, 88, 895-917. doi: 10.1037/ 0022-3514.88.6.895

Skitka, L. J., Liu, J., Yang, Y., Chen, H., Liu, L., \& Xu, L. (2012). Exploring the cross-cultural generalizability and scope of morally motivated intolerance. Social Psychological and Personality and Science, 4(3), 324-331. doi: 10.1177/ 1948550612456404

Skitka, L. J., \& Morgan, G. S. (2014). The social and political implications of moral conviction. Advances in Political Psychology, 35, 95-110. https://doi.org/ 10.1111/pops. 12166
Skitka, L. J., \& Wisneski, D. C. (2010). Moral conviction and emotion. Emotion Review, 3, 328-330. doi: 10.1177/1754073911402374

Tan, L. B. G., Lo, B. C. Y., \& Macrae, N. (2014). Brief mindfulness meditation improves mental state attribution and empathizing. PLoS ONE, 9, 1-5. https: //doi.org/10.1371/journal.pone.0110510

Teasdale, J. D., Segal, Z. V., Williams, M. G. J., Ridgeway, V. A., Soulsby, J. M., \& Lau, M. A. (2000). Prevention of relapse/recurrence in major depression by mindfulness-based cognitive therapy. Journal of Consulting and Clinical Psychology, 68, 615623. doi:10.1037/0022-006X.68.4.615

van Zomeren, M., Postmes, T., \& Spears, R. (2012). On conviction's collective consequences: Integrating moral conviction with the social identity model of collective action. British Journal of Social Psychology, 51, 52-71. doi: 10.1111/j.2044-8309.2010. 02000.x

Westfall, J., Van Boven, L., Chambers, J. R., \& Judd, C. M. (2015). Perceiving political polarization in the United States: Party identity strength and attitude extremity exacerbate the perceived partisan divide. Perspectives on Psychological Science, 10(2), 145158. doi: $10.1177 / 1745691615569849$

Wisneski, D. C., \& Skitka, L. J. (2017). Moralization through moral shock: Exploring emotional antecedents to moral conviction. Personality and Social Psychology Bulletin, 43, 139-150. https:// doi.org/10.1177/0146167216676479

Wright, J. C., Cullum, J., \& Schwab, N. (2008). The cognitive and affective dimensions of moral conviction: Implications for attitudinal and behavioral measures of interpersonal tolerance. Personality and Social Psychology Bulletin, 11, 1461-1476. doi: 10.1177/0146167208322557

Zanesco, A. P., King, B. G., MacLean, K. A., \& Saron, C. D. (2013). Executive control and felt concentrative engagement following intensive meditation training. Frontiers in Human Neuroscience, 7, 566. doi: $10.3389 /$ fnhum.2013.00566 